\title{
Structural Changes in Silica Glass under the Action of Electron Beam Irradiation: The Effect of Irradiation Dose
}

\author{
A. I. Sidorov ${ }^{a, b}, *$, D. A. Kirpichenko ${ }^{c}$, U. V. Yurina ${ }^{c}$, and O. A. Podsvirov ${ }^{c}$ \\ ${ }^{a}$ ITMO University, St. Petersburg, 197101 Russia \\ ${ }^{b}$ Saint-Petersburg Electrotechnical University “LETI”, St. Petersburg, 197376 Russia \\ ${ }^{c}$ Saint-Petersburg Polytechnical University, St. Petersburg, 195251 Russia \\ *e-mail: sidorov@oi.ifmo.ru
}

Received August 20, 2020; revised September 29, 2020; accepted December 4, 2020

\begin{abstract}
Structural changes in silica glass, produced by electron irradiation, with electrons energies of $50 \mathrm{keV}$ and doses of 5-80 $\mathrm{mC} / \mathrm{cm}^{2}$ were studied by Raman spectroscopy in frequency ranges of 300-550 and of $700-1500 \mathrm{~cm}^{-1}$. It is shown that for irradiation doses less than $5 \mathrm{mC} / \mathrm{cm}^{2}$ the decrease of siloxane rings concentration in glass takes place. The further increase of dose results in the increase of siloxane rings concentration in glass network after irrsdiation. And for doses of more than $40 \mathrm{mC} / \mathrm{cm}^{2}$ the whole destruction of glass structure and its structural units takes place. The obtained results for silica glass were compared with similar results for crystalline quartz.
\end{abstract}

Keywords: silica glass, glass structure, electron beam, Raman spectroscopy

DOI: $10.1134 / \mathrm{S} 1087659621020140$

\section{INTRODUCTION}

Focused electron beam with relatively low electrons energies (less than $100 \mathrm{keV}$ ) is a powerful tool for local modification of optical properties of optical materials, such as glasses and crystals. By electron irradiation the crystallization processes in glasses can be initiated $[1,2]$. Metal nanoparticles $(\mathrm{Ag}, \mathrm{Au}, \mathrm{Cu}$, $\mathrm{Na}, \mathrm{K}, \mathrm{Li}$ etc.) can be formed locally under the surface of metal-containing glasses and crystals [3-7]. Optical and plasmonic waveguides can be written by scanning electron beam on glass or crystal surfaces [3, 8-10]. Electron beam irradiation of glasses can enhance nonlinear optical properties of glasses [11] and produce luminescent centers in them [6,7]. The choice of electron energy makes possible to dissolute thin metal films in glasses or to form metal films on the surfaces of metal-containing glasses $[12,13]$. The advantage of electron beam with relatively low electrons energy is that it can be focused into a spot with the size less than $10 \mathrm{~nm}$. It makes possible to fabricate nanostructures in glasses and crystals for integrated optics, nanophotonics and nanoplasmonics.

The main processes, which take place during focused electron beam action on glasses are the following: (i) appearance of negatively charged area under the sample surface, formed by thermalized electrons $[3,14]$; (ii) field migration of positive and mobile metal ions to the negatively charged area, thus producing spatial re-distribution of glass components and local change of its chemical properties [3, 15]; (iii) breaking of chemical bonds by fast electrons, thus producing structural defects and changing the structure and other properties of glass. To study the features of the third process the most convenient material is pure silica glass without any dopants.

The influence of ionizing radiations (such as $\mathrm{X}$-rays, $\boldsymbol{\gamma}$-rays, heavy ions beams, synchrotron and UV irradiation, etc.) on structural and other properties of glasses was studied in [16-35]. In [35] structural changes in silica glass after electron irradiation with electrons energy $2.5 \mathrm{MeV}$ was studied by methods of Raman spectroscopy. There are very few works discussing the influence on glasses of electrons with relatively low energies $(1-100 \mathrm{keV})$, though this interval of electrons energies is most promising for the use in nanotechnologies. And it is important for further investigations to study the influence of electron irradiation on "pure" $\mathrm{SiO}_{2}$, such as silica glass.

The goal of the present work was the study of the influence of electron irradiation dose, for electrons with energy of $50 \mathrm{keV}$, on the structural changes of silica glass by methods of Raman spectroscopy.

\section{EXPERIMENTAL}

In our experiments we used polished plates of optical silica glass KU-2 with the size of $15 \times 15 \mathrm{~mm}^{2}$ and $3 \mathrm{~mm}$ thick. The electron irradiation was carried out in a JEBD-2 scanning electron microscope. The electrons energy $E$ was $50 \mathrm{keV}$, the irradiation doses $D$ were 
varied in the range of $5-80 \mathrm{mC} / \mathrm{cm}^{2}$ for electron current density of $50 \mu \mathrm{A} / \mathrm{cm}^{2}$. The electron irradiation was carried out at a room temperature, but the calculation have shown that near-surface glass layer during electron irradiation for $E=50 \mathrm{keV}$ and $D=50 \mathrm{mC} / \mathrm{cm}^{2}$ is heated up to $150^{\circ} \mathrm{C}$. The calculation was performed by solving of non-stationary equation of thermal conductivity with the assumption that all the energy of primary electrons is transformed to heat in near-surface glass layer of $50 \mu \mathrm{m}$ thick. The electron beam diameter on the glass surface was $1.5-2 \mathrm{~mm}$ for the convenience of optical measurements. Aluminum films of $80 \mathrm{~nm}$ thick were deposited on the samples surfaces for removing the surface charge, which appears on a glass surface during electron irradiation. After irradiation, these films were removed by etching in an aqueous solution of $\mathrm{KOH}$.

Raman spectra were measured using inVia Raman microscope spectrometer (Renishaw) at room temperature. It is known that some types of radiation defects are non-stable and disappear after some time. Preliminary studies have shown that strong changes in Raman spectra stop approximately 10 days later after electron irradiation. So, spectral measurements were performed after the mentioned time interval.

\section{EXPERIMENTAL RESULTS}

Figure 1a (curve 1) shows the Raman spectrum of silica glass before electron irradiation. One can see that spectrum consists of three main bands: the structured and intense band in frequency range of 200$700 \mathrm{~cm}^{-1}$ (it can be decomposed by 4 Gaussians), weak bands with maxima at 800 and at $1075 \mathrm{~cm}^{-1}$. The band at frequencies less than $200 \mathrm{~cm}^{-1}$ is the superposition of Boson peak, typical one for vibrations in disordered media [36, 37], and Raleigh scattering. According to [38-40] the band with maximum at $v=$ $1075 \mathrm{~cm}^{-1}$ can be assigned to Si-NBO (NBO - nonbridging oxygen) stretching mode in $\mathrm{Q}^{3}$ unit (see Fig. 1b). The band at $v=800 \mathrm{~cm}^{-1}$ is related to the symmetric stretching mode of anionic structural unit $\left(\mathrm{SiO}_{4}\right)^{4-}$. The bands with $v=600 \mathrm{~cm}^{-1}$ can be related to the symmetric oxygen breathing vibration of four-fold and three-fold siloxane rings, consisting of $\mathrm{SiO}_{4}$ tetrahedra (see Fig. 1b). The bands at about 420 and $465 \mathrm{~cm}^{-1}$ can be attributed to vibrations of $\mathrm{Si}-\mathrm{O}-\mathrm{Si}$ bonds in fourfold, five-fold, and six-fold siloxane rings. The band at $v=$ $330 \mathrm{~cm}^{-1}$ can be attributed to $\mathrm{Si}_{2} \mathrm{O}_{4}$ in 3D-framework [41].

For the comparison in Fig. 1a are shown Raman spectra of sodium-containing silicate glass with the composition $\mathrm{Na}_{2} \mathrm{O}-\mathrm{SiO}_{2}-\mathrm{CaO}$ (curve 2) and of crystalline $\alpha$-quartz (curve 3 ). One can see that for silicate glass the ratio of Raman bands intensities at $v \approx 400 \mathrm{~cm}^{-1}$ and $v \approx 1000 \mathrm{~cm}^{-1}$ differs from the ratio of the same bands intensities for silica glass. It indicates the con- siderable increase of concentration of glass network defects in silicate glass, such as $\mathrm{Q}^{2}$ and $\mathrm{Q}^{3}$ (see Fig. 1b). Raman spectrum of crystalline $\alpha$-quartz consists of two main bands: narrow band at $v=465 \mathrm{~cm}^{-1}$ and wide structured band in frequency region of 700$1100 \mathrm{~cm}^{-1}$. The first band can be attributed to $\mathrm{Si}-\mathrm{O}-\mathrm{Si}$ stretching-bending modes in 6-fold siloxane rings [42]. The second band can be attributed to the point defects in crystalline quartz, similar to $\mathrm{Si}-\mathrm{NBO}$.

After electron irradiation no visible changes in irradiated areas of the samples were observed. Figure 2 shows Raman spectra of silica glass in frequency range of $300-550 \mathrm{~cm}^{-1}$ before and after electron irradiation with different irradiation doses. Figure 3 shows the influence of irradiation dose on Raman bands intensity for $v=465$ and $420 \mathrm{~cm}^{-1}$. It can be seen from Figures that for doses range of $0-5 \mathrm{mC} / \mathrm{cm}^{2}$ the decrease of bands intensity in their maxima takes place. For $D=10-40 \mathrm{mC} / \mathrm{cm}^{2}$ the increase of bands intensity is observed, and they became more structured. After irradiation with $D=10 \mathrm{mC} / \mathrm{cm}^{2}$ new band with maximum at $v=375 \mathrm{~cm}^{-1}$ appears. For irradiation dose $D=40 \mathrm{mC} / \mathrm{cm}^{2}$ the bands intensity returns to the initial state. When $D$ exceeds $40 \mathrm{mC} / \mathrm{cm}^{2}$ the intensity of bands decreases with the increase of irradiation dose. The change of bands intensity is accompanied by the spectral shift of their maxima. The dependencies of intensity on irradiation dose for $v=465$ and $420 \mathrm{~cm}^{-1}$ are similar in the limit of measurements error (Fig. 3).

Figure 4 shows Raman spectra of silica glass in frequency range of $700-1300 \mathrm{~cm}^{-1}$ before and after electron irradiation with different irradiation doses. It can be seen from Fig. 4 that there are, at least, 6 Raman bands with different intensities in this spectral region. It indicates the presence in silica glass of several types of defects with different properties [38-40]. The dose of electron irradiation effects on all bands, changing their intensity and, in some cases, produces spectral shift of the bands. Below we discuss the influence of electron irradiation dose only on three bands, which can be accurately attributed. These bands have maxima at $v=800,1000$ and $1075 \mathrm{~cm}^{-1}$. The first band $\left(v=800 \mathrm{~cm}^{-1}\right)$ corresponds to the symmetric stretching mode of anionic structural unit $\left(\mathrm{SiO}_{4}\right)^{4-}$ [39]. The second band with maximum at $v=1000 \mathrm{~cm}^{-1}$ is the superposition of two bands: $\mathrm{Si}-\mathrm{NBO}$ stretching mode in $\mathrm{Q}^{3}$ unit and $\mathrm{Si}-\mathrm{BO}$ vibration mode in not fully polymerized structural units $\mathrm{Q}^{3}$ or $\mathrm{Q}^{2}$. The third band with maximum at $v=1075 \mathrm{~cm}^{-1}$ can be assigned to $\mathrm{Si}-\mathrm{NBO}$ stretching mode in $\mathrm{Q}^{3}$ unit.

Figure 5 shows the influence of irradiation dose on these Raman bands intensities in maximum. One can see that the increase of irradiation dose from 0 up to $10 \mathrm{mC} / \mathrm{cm}^{2}$ results in the considerable increase of 


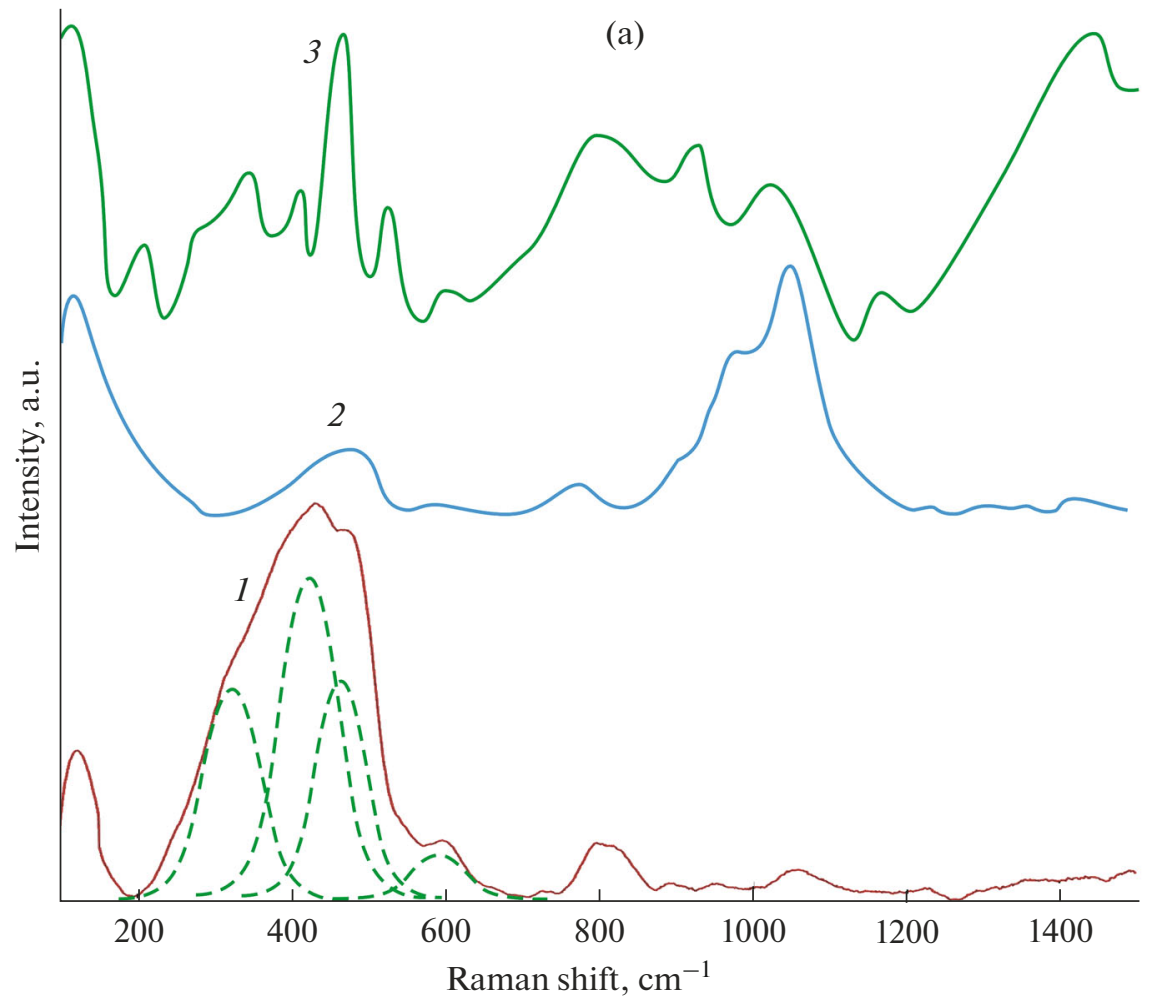

(b)

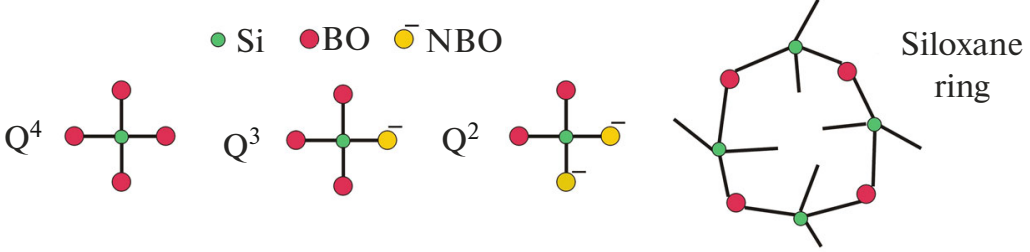

Fig. 1. Raman spectra of silica glass (1), sodium-containing silicate glass (2) and crystalline $\alpha$-quartz (3) before electron irradiation. Green dashed curves are the decomposition by Gaussians. The spectra of silicate glass and $\alpha$-quartz are shifted up (a); some structural units of silica and silicate glasses. BO-bridging oxygen, NBO-non-bridging oxygen (b). Adapted from [38-41].

bands intensities. The further increase of irradiation dose is followed by the decrease of intensity for all three bands. The amplitudes of the bands for $D=$ $80 \mathrm{mC} / \mathrm{cm}^{2}$ are less than in non-irradiated sample.

For the comparison the sample of crystalline $\alpha$-quartz was also irradiated by electrons in the similar conditions conditions. Figure 6 shows the influence of irradiation dose on Raman band intensity at $v=465 \mathrm{~cm}^{-1}$ (see also Fig. 1a, curve 3). It can be seen from the Figure that electron irradiation of crystalline quartz results in monotonous decrease of the band intensity with the increase of irradiation dose. The most considerable changes in band amplitude are observed for $D<20 \mathrm{mC} / \mathrm{cm}^{2}$. The influence of electron irradiation on Raman band in frequency range of $700-1100 \mathrm{~cm}^{-1}$ (see Fig. 1a, curve 3), which is connected with crystalline defects, is very weak and does not exceed measurements error.

\section{DISCUSSION}

It must be noted that structural changes in glass take place not only during electron irradiation, but also after irradiation. The reason of it is that some radiation defects, which appear in during electron irradiation, are non-stable [43], and after electron irradiation the processes, involving them, can continue in glass. Let's consider the main processes, which cause structural changes during electron irradiation specifically in silica glass. The calculations (by Monte-Carlo method) have shown that maximum of energy losses for electrons with $E=50 \mathrm{keV}$ is located in depth of 25-30 $\mu \mathrm{m}$ under the glass surface. So, all the changes in glass during electron irradiation are located in a subsurface layer of that thickness. As it was mentioned in Introduction the main processes, which take place in glasses during electron irradiation, are the break of chemical bonds of glass network and the field migration of positive mobile ions to the nega- 

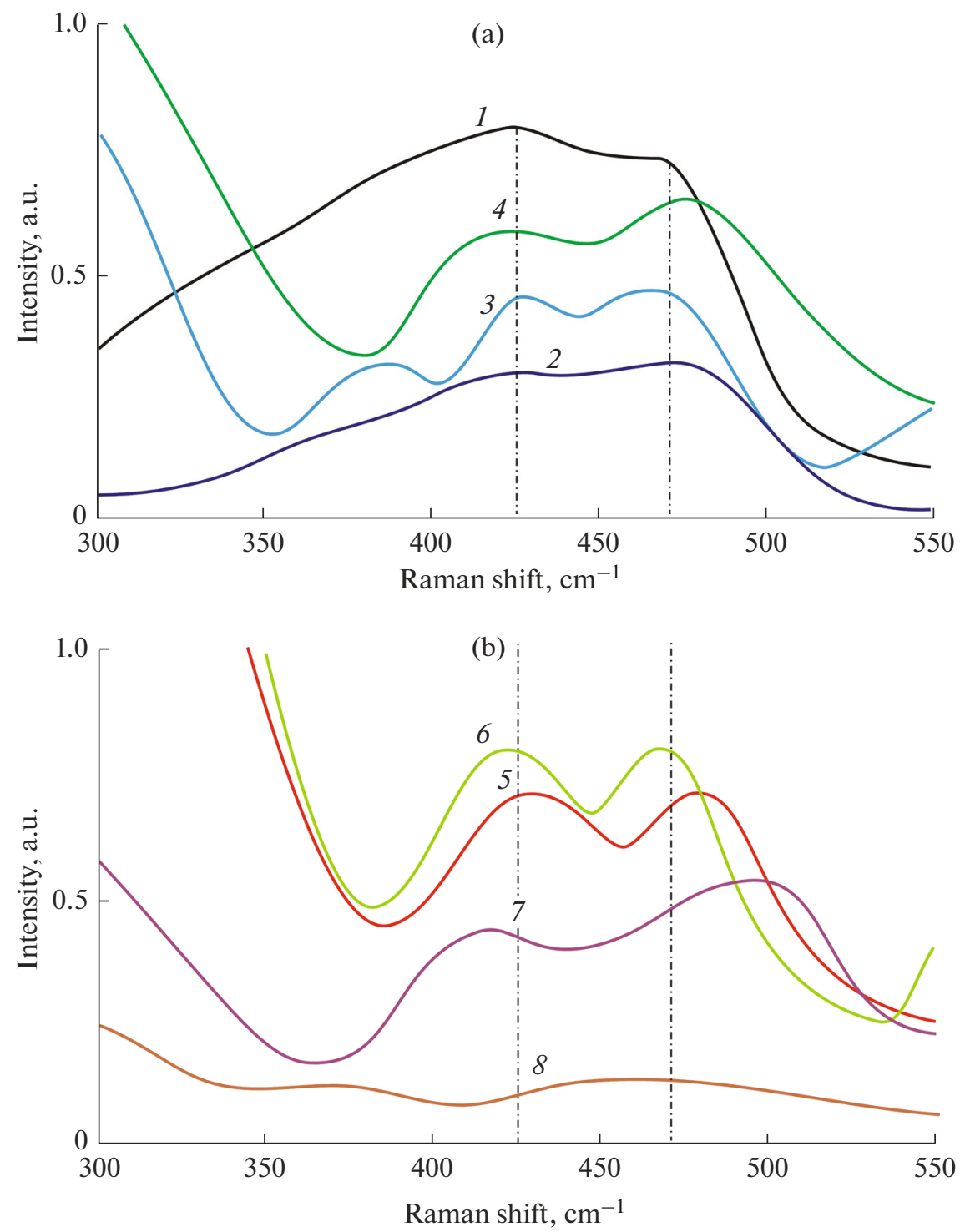

Fig. 2. Raman spectra of silica glass in the frequency range $700-1300 \mathrm{~cm}^{-1}$. Irradiation doses $D$ in $\mathrm{mC} / \mathrm{cm}^{2}: 1-0,2-5,3-10$, 4-15 (a); Irradiation doses $D$ in $\mathrm{mC} / \mathrm{cm}^{2}: 5-30,6-40,7-60,8-80$ (b). Dashed lines are spectral position of bands, analyzed below.

tively charged region, formed by thermalized electrons. The components of silica glass, $\mathrm{Si}$ and $\mathrm{O}$ in ionic state, have very low mobility at room temperature, so there is very low probability of their spatial redistribution during electron irradiation. Thus, the main process, which causes the changes in silica glass structure, is the break of chemical bonds of glass network by fast electrons. It is known that the binding energy of $\mathrm{Si}-\mathrm{O}$ bond is approximately $8 \mathrm{eV}$. So, electrons with this or higher energies can break bonds in siloxane rings, decreasing their concentration in glass. This is confirmed by the decrease for $D \leq 5 \mathrm{mC} / \mathrm{cm}^{2}$ of intensities of Raman bands at $v=420$ and $465 \mathrm{~cm}^{-1}$, which can be attributed to vibrations of $\mathrm{Si}-\mathrm{O}-\mathrm{Si}$ bonds in siloxane rings (see Fig. 3). At the same time the concentration of glass network defects, such as $\mathrm{Q}^{2}, \mathrm{Q}^{3}$ and $\left(\mathrm{SiO}_{4}\right)^{4-}$, for $D \leq 10 \mathrm{mC} / \mathrm{cm}^{2}$ increases (see Fig. 5).
As for low irradiation doses the concentration of radiation induced defects is low, and they are located far from each other, the restoration of siloxane rings after electron irradiation is difficult. But it can be seen from Figs. 3 and 5 that for higher doses the increase of siloxane rings concentration and the decrease of defects concentration take place. It is evident that the higher is the irradiation dose the higher concentration of defects will appear in glass. And at high concentration of defects it is easier for them after electron irradiation to form new siloxane rings, thus restoring the structure of glass network. When electron irradiation dose exceeds $40 \mathrm{mC} / \mathrm{cm}^{2}$ the decrease of Raman bands intensity at 420 and $465 \mathrm{~cm}^{-1}$ is observed. This can be explained by the destruction of $\mathrm{Q}^{2}, \mathrm{Q}^{3}$ and $\mathrm{Q}^{4}$ structural units, which makes the restoration of siloxane rings impossible. 


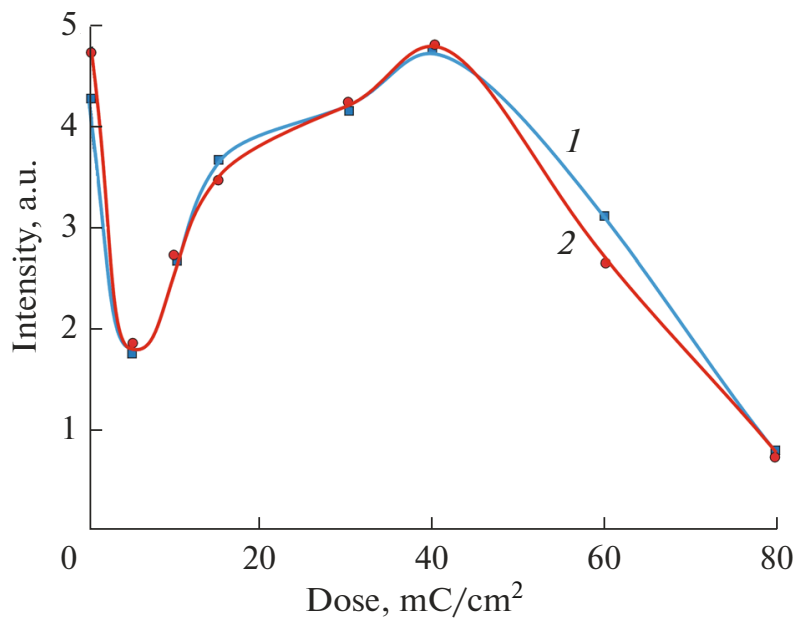

Fig. 3. Influence of irradiation dose on Raman bands intensity at $\mathrm{v}=465 \mathrm{~cm}^{-1}(1)$ and $420 \mathrm{~cm}^{-1}(2)$.
Strong structural changes in silica glass after electron irradiation for large irradiation doses are confirmed by considerable change of glass chemical etching rate in the irradiated zone. Figure 7 shows the photo of silica glass surface near irradiated zone, made by optical microscope. In this case electron irradiation dose was $D=80 \mathrm{mC} / \mathrm{cm}^{2}$, chemical etching was performed in HF (10\%) during $3 \mathrm{~h}$. One can see that after etching the pit appears in the irradiated zone. The rate of etching in this region increased approximately by 2 times.

It can be seen from Figs. 2 and 4 that electron irradiation results in spectral shift of some Raman bands, as in spectral range of siloxane rings vibrations, so in the spectral range of bonds vibrations in glass network defects. In the first case, it can be explained by the change of number of elements in siloxane rings, restored after electron irradiation, in comparison with
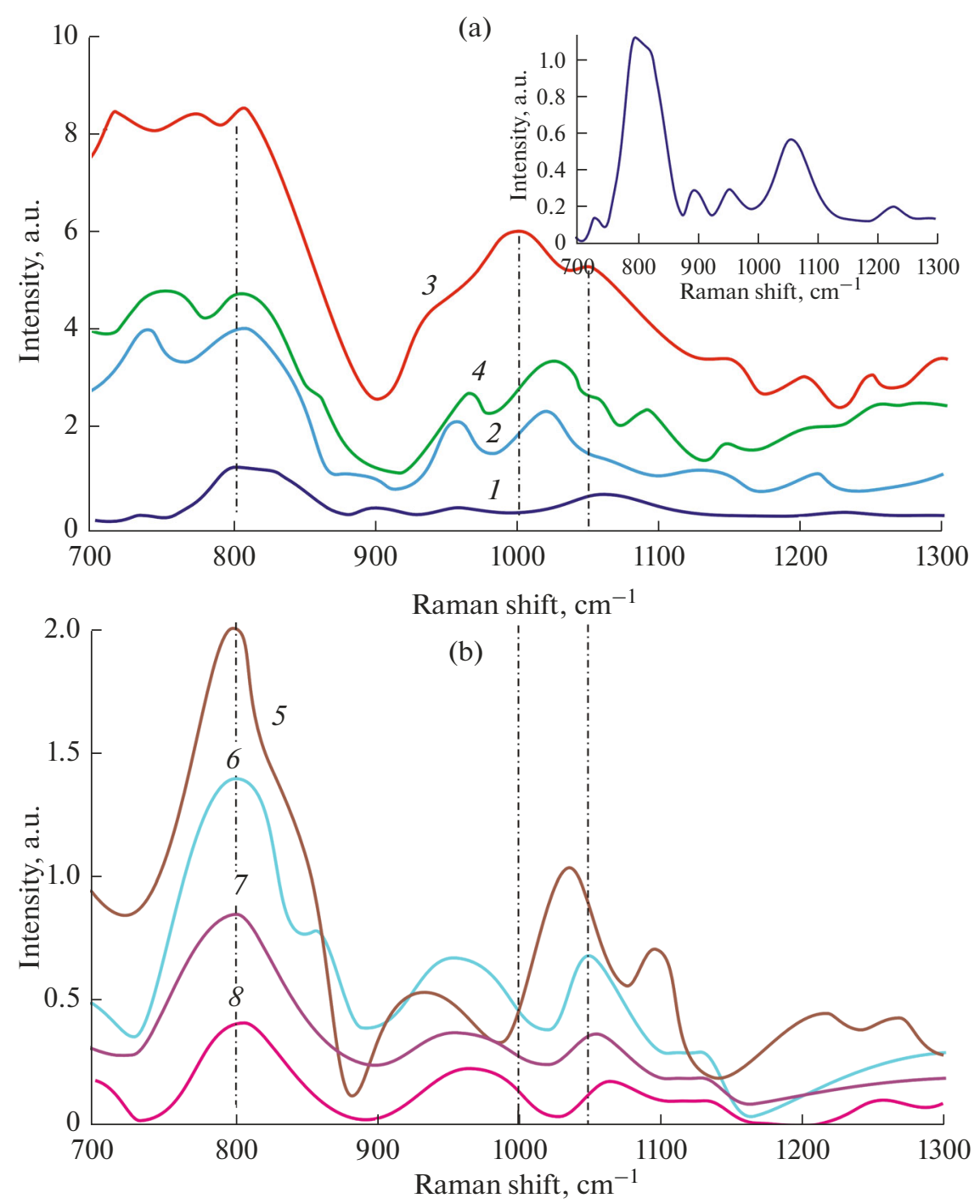

Fig. 4. Raman spectra of silica glass in the frequency range $700-1300 \mathrm{~cm}^{-1}$. Irradiation doses $D$ in $\mathrm{mC} / \mathrm{cm}^{2}: 1-0,2-5,3-10$, 4-15. Inset-curve 1 (a); Irradiation doses $D$ in $\mathrm{mC} / \mathrm{cm}^{2}: 5-30,6-40,7-60,8-80$ (b). Dashed lines are spectral position of bands, analyzed below. 


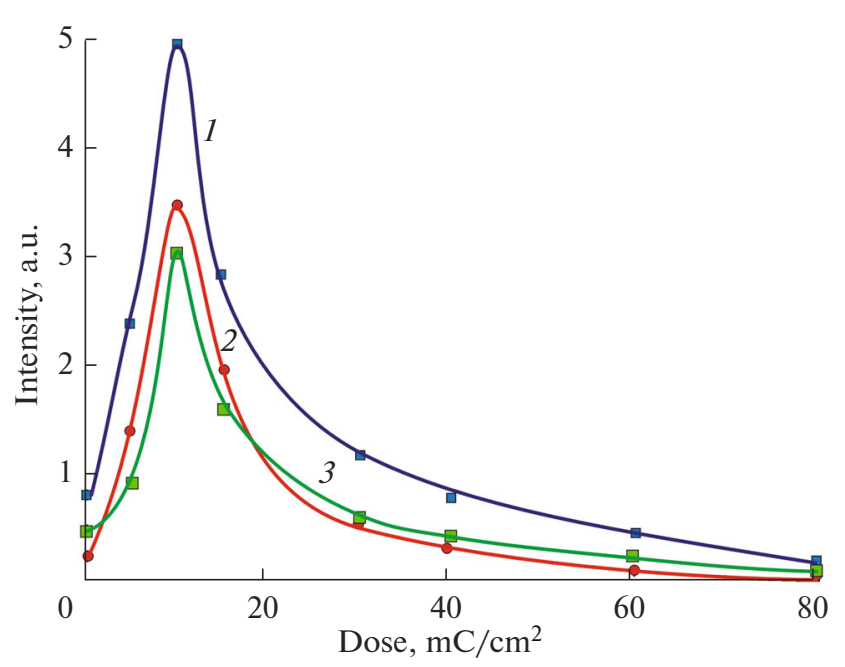

Fig. 5. Influence of irradiation dose on Raman bands intensity at $v=800(1), 1000(2)$, and $1075 \mathrm{~cm}^{-1}(3)$.

pristine glass. The change of siloxane ring size leads to the change of $\mathrm{Si}-\mathrm{O}$ chemical bond length. The other reason is the appearance of $\mathrm{Si}-\mathrm{O}-\mathrm{O}-\mathrm{Si}$ units in restored siloxane rings, as a result of connection of two NBO's. In the second case, at high concentration of radiation-induced defects the interaction between them can take place. This can influence on chemical bonds lengths in defect structural units, such as $\mathrm{Q}^{2}$ and $\mathrm{Q}^{3}$.

The dependence of Raman band intensity on electron irradiation dose at $v=465 \mathrm{~cm}^{-1}$ for crystalline $\alpha$ -

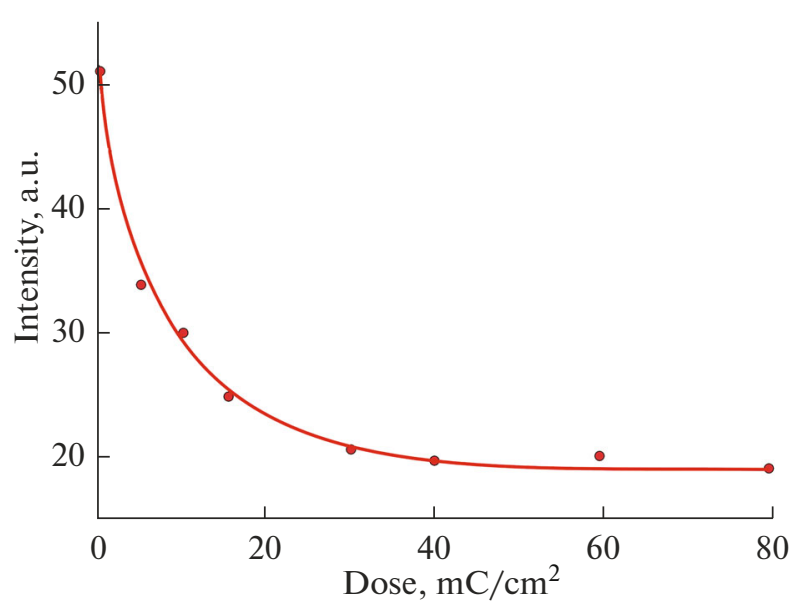

Fig. 6. Influence of irradiation dose on Raman band intensity at $v=465 \mathrm{~cm}^{-1}$ for crystalline $\alpha$-quartz.

quartz differs from the similar dependence for silica glass: the Raman band intensity monotonously decreases with the increase of irradiation dose (see Fig. 6). It can be explained by the fact that crystalline quartz is more static system then silica glass, and dynamic processes after electron irradiation, including siloxane rings restoration, occur at room temperature too slow. The weak influence of electron irradiation on Raman band, connected with defects in quartz, is caused by the difference of irradiation induced defects types, in comparison with silica glass.

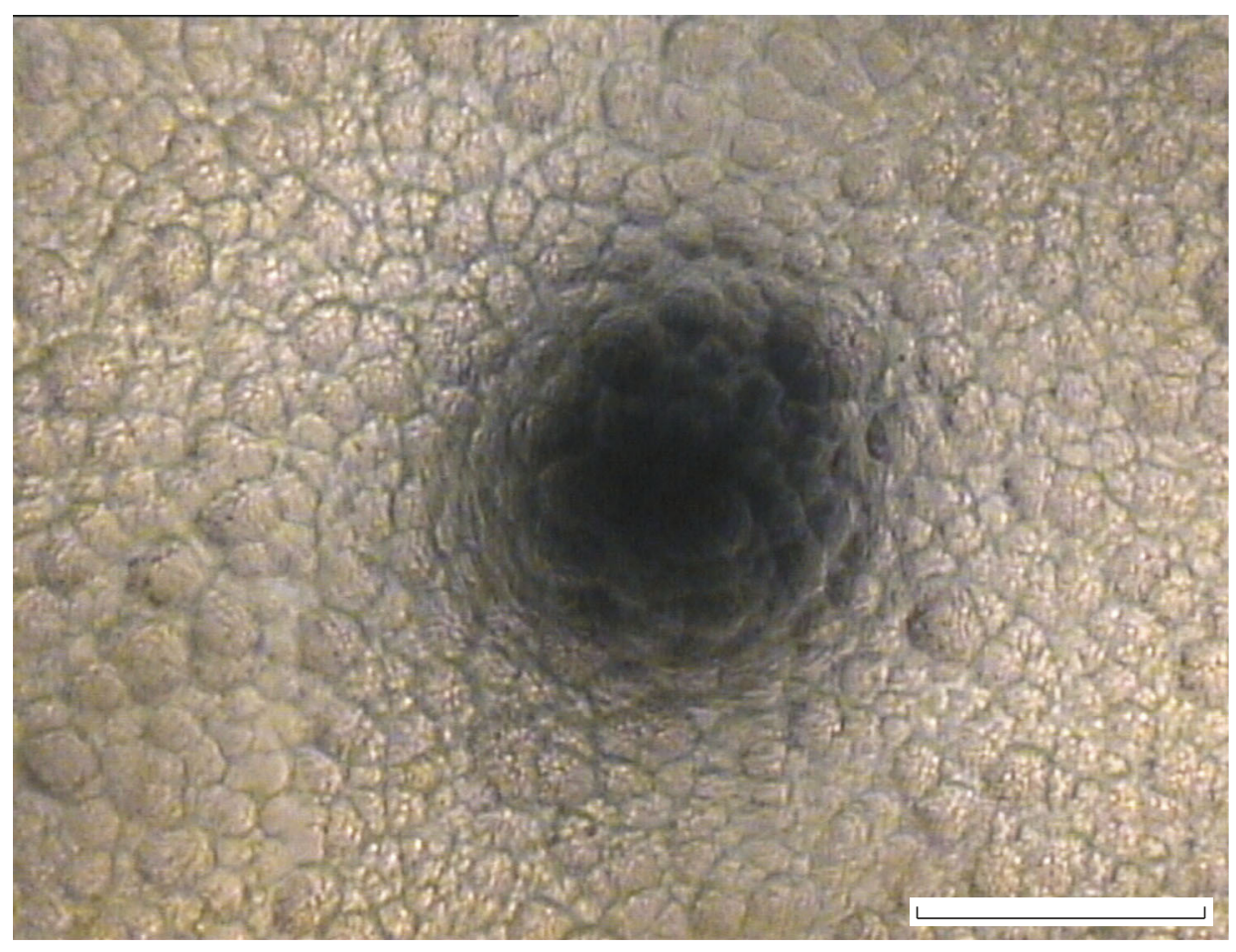

Fig. 7. Photo of silica glass surface near the irradiated area after chemical etching. Scale is $1 \mathrm{~mm}$. 
The obtained results can be compared with the results, described in [35], where silica glass was irradiated by electrons with energy of $2.5 \mathrm{MeV}$ and after that was studied by Raman spectroscopy. In that work only weak structural changes were observed in silica glass after electron irradiation. The reason of it is that electrons with high energies have weak interaction with glass and pass through the glass sample with small energy losses. Electrons with $E=50 \mathrm{keV}$ lose all their energy in a glass layer of $25-30 \mu \mathrm{m}$ thick, and the main part of this energy is spend to chemical bands break. That's why, electron beams with relatively low electrons energies are promising for modification of optical properties of optical materials.

\section{CONCLUSIONS}

Experiments have shown that for $E=50 \mathrm{keV}$ there are three specific intervals of electron irradiation doses, which produce different changes in silica glass structure. In the first one, for doses less, than $10 \mathrm{mC} / \mathrm{cm}^{2}$, the destruction of siloxane rings, composing glass network, takes place. In the second one, for doses $10-40 \mathrm{mC} / \mathrm{cm}^{2}$, the restoration of siloxane rings after electron irradiation takes place, because of high concentration of structural defects, such as $\mathrm{Q}^{2}$ and $\mathrm{Q}^{3}$. In the third one, for doses more, than $40 \mathrm{mC} / \mathrm{cm}^{2}$, the restoration of siloxane rings is not observed. The reason of it is the destruction by electrons of $\mathrm{Q}^{2}, \mathrm{Q}^{3}$ and $\mathrm{Q}^{4}$ structural units, which can compose siloxane rings. The influence on electron irradiation dose on crystalline quartz structure differs considerably from the influence of irradiation dose on structure of silica glass.

\section{FUNDING}

This work was financially supported by Russian Science Foundation (Project no. 20-19-00559.

\section{CONFLICT OF INTEREST}

The authors declare that they have no conflicts of interest.

\section{OPEN ACCESS}

This article is licensed under a Creative Commons Attribution 4.0 International License, which permits use, sharing, adaptation, distribution and reproduction in any medium or format, as long as you give appropriate credit to the original author(s) and the source, provide a link to the Creative Commons license, and indicate if changes were made. The images or other third party material in this article are included in the article's Creative Commons license, unless indicated otherwise in a credit line to the material. If material is not included in the article's Creative Commons license and your intended use is not permitted by statutory regulation or exceeds the permitted use, you will need to obtain permission directly from the copyright holder. To view a copy of this license, visit http://creativecommons.org/licenses/by/4.0/.

\section{REFERENCES}

1. Jianga, N., Qui, J., and Spence, J.C.H., Precipitation of $\mathrm{Ge}$ nanoparticles from $\mathrm{GeO}_{2}$ glasses in transmission electron microscope, Appl. Phys. Lett., 2005, vol. 86, p. 143112.

2. Jianga, N., Wu, B., Qiu, J., and Spence, J.C.H., Precipitation of nanocrystals in glasses by electron irradiation: An alternative path to form glass ceramics?, Appl. Phys. Lett., 2007, vol. 90, p. 161909.

3. Ignatiev, A.I., Nashchekin, A.V., Nevedomskii, V.M., Podsvirov, O.A., Sidorov, A.I., Solov'ev, A.P., and Usov, O.A., Formation of silver nanoparticles in photothermorefractive glasses during electron irradiation, Tech. Phys., 2011, vol. 81, pp. 662-665.

4. Podsvirov, O.A., Sidorov, A.I., Tsekhomskii, V.A., and Vostokov, A.V., Formation of copper nanocrystals in photochromic glasses under electron irradiation and heat treatment, Phys. Solid State, 2010, vol. 52, pp. 1906-1909.

5. Bochkareva, E.S., Nikonorov, N.V., Podsvirov, O.A., Prosnikov, M.A., and Sidorov, A.I., The formation of sodium nanoparticles in alkali-silicate glass under the action of the electron beam and thermal treatments, Plasmonics, 2016, vol. 11, pp. 241-246.

6. Bochkareva, E.S., Sidorov, A.I., Yurina, U.V., and Podsvirov, O.A., Formation of metal nanoparticles in $\mathrm{MgF}_{2}, \mathrm{CaF}_{2}$ and $\mathrm{BaF}_{2}$ crystals under the electron beam irradiation, Nucl. Instrum. Methods Phys. Res., Sect. B, 2017, vol. 403, pp. 1-6.

7. Ilina, E.A., Sidorov, A.I., Yurina, U.V., and Podsvirov, O.A., Effect of electron beam irradiation dose on luminescence and optical absorption of LiF crystals, Nucl. Instrum. Methods Phys. Res., Sect. B, 2017, vol. 412, pp. 28-33.

8. Ogorodnikov, I.N., Pustovarov, V.A., Omelkov, S.I., and Kirm, M., Effect of an electron beam irradiation on optical and luminescence properties of $\mathrm{LiBaAlF}_{6}$ single crystals, Opt. Mater., 2017, vol. 69, pp. 344-351.

9. Volk, T.R., Kokhanchik, L.S., Gainutdinov, R.V., Bodnarchuk, Y.V., Shandarov, S.M., Borodin, M.V., Lavrov, S.D., Liu, H., and Chen, F., Microdomain patterns recorded by an electron beam in He-implanted optical waveguides on X-cut $\mathrm{LiNbO}_{3}$ crystals, J. Lightwave Technol., 2015, vol. 33, pp. 4761-4766.

10. Podsvirov, O.A., Sidorov, A.I., and Churaev, D.V., Specific features of the formation of optical waveguides in silicate glass at high energy and dose of electron irradiation, Tech. Phys., 2014, vol. 59, pp. 1674-1678.

11. Kazansky, P.G., Kamal, A., and Russell, P.S.J., High second-order nonlinearities induced in lead silicate glass by electron-beam irradiation, Opt. Lett., 1993, vol. 18, pp. 693-695.

12. Brunov, V.S., Podsvirov, O.A., Sidorov, A.I., and Churaev, D.V., Formation of silver thin films and nanoparticles inside and on the surface of silver-containing glasses by electron irradiation, Tech. Phys., 2014, vol. 84, pp. 1215-1219.

13. Komissarenko, F.E., Mukhin, I.S., Golubok, A.O., Nikonorov, N.V., Prosnikov, M.A., and Sidorov, A.I., Effect of electron beam irradiation on thin metal films on glass surfaces in a submicrometer scale, $J . M i-$ cro/Nanolithogr., 2016, vol. 15, p. 013502. 
14. Touzin, M., Goeriot, D., Guerret-Piecort, C., Juve, D., Treheux, D., and Fitting, H.-J., Electron beam charging of insulators with surface layer and leakage currents, J. Appl. Phys., 2006, vol. 99, p. 114110.

15. Gedeon, O., Zemek, J., and Jurek, K., Changes in alkali-silicate glasses induced with electron irradiation, $J$. Non-Cryst. Solids, 2008, vol. 354, pp. 1169-1171.

16. Fuhrmann, S., Schumacher, D., Herbst, J., and Wondraczek, L., Irradiation induced particle formation in Gg-doped sulfophosphate glass, J. Non-Cryst. Solids, 2014, vol. 401, pp. 82-86.

17. Eichelbaum, M., Rademann, K., Hoell, A., Tatchev, D.M., Weigel, W., Stoßer, R., and Pacchioni, G., Photoluminescence of atomic gold and silver particles in sodalime silicate glasses, Nanotecnology, 2008, vol. 19, p. 135701 .

18. Murashov, A.A., Sidorov, A.I., Stolyarchuk, M.V., and Boiko, M.E., Effect of X-ray irradiation and thermal treatment on luminescent properties of barium-phosphate glasses, doped with silver and copper, J. NonCryst. Solids, 2017, vol. 477, pp. 1-6.

19. Zheng, W. and Kurobori, T., Assignments and optical properties of X-ray-induced colour centres in blue and orange radiophotoluminescent silver-activated glasses, J. Lumin., 2011, vol. 131, pp. 36-40.

20. De Lamaestre, R.E., Bea, H., Bernas, H., Belloni, J., and Marignier, J.L., Irradiation-induced Gg nanocluster nucleation in silicate glasses: Analogy with photography, Phys. Rev. B, 2007, vol. 76, p. 205431.

21. Schreurs, J.W., Study of some trapped hole centers in X-irradiated alkali silicate glasses, J. Chem. Phys., 1967, vol. 47, pp. 818-830.

22. Sheng, J., Kadono, K., and Yazawa, T., Easily recyclable coloured glass by X-ray irradiation induced coloration, Eur. J. Glass Sci. Technol. B, 2002, vol. 43, pp. 2594-2601.

23. Sheng, J., Kadono, K., and Yazawa, T., X-ray irradiation on the soda-lime container glass, Appl. Radiat. Isotopes, 2002, vol. 56, pp. 621-625.

24. Mackey, J.H., Smith, H.L., and Halperin, A., Optical studies in X-irradiated high purity sodium silicate glasses, J. Phys. Chem. Solids, 1966, vol. 27, pp. 1759-1772.

25. Wu, Y.J., Yang, X., and Zhang, J., UV-laser irradiation on the soda-lime silicate glass, Int. J. Hydrogen Energy, 2009, vol. 34, pp. 1123-1125.

26. Suszynska, M. and Macalik, B., Optical studies in gamma-irradiated commercial soda-lime silicate glasses, Nucl. Instrum. Methods Phys. Res., Sect. B, 2001, vol. 179, pp. 383-388.

27. Skuja, L., Optically active oxygen-deficiency-related centers in amorphous silicon dioxide, J. Non-Cryst. Solids, 1998, vol. 239, pp. 16-48.

28. Tsai, H.-S., Chao, D.-S., Wu, Y.-H., He, Y.-T., Chueh, Y.-L., and Liang, J.H., Spectroscopic investigation of gamma radiation-induced coloration in silicate glass for nuclear applications, J. Nucl. Mater., 2014, vol. 453, pp. 233-238.

29. Xinjie, F., Lixin, S., and Jiacheng, L., Radiation induced color centers in cerium-doped and cerium-free multicomponent silicate glasses, J. Rare Earths, 2014, vol. 32, pp. 1037-1042.
30. Dmitryuk, A.V., Paramzina, S.E., Perminov, A.S., Solov'eva, N.D., and Timofeeva, N.T., The influence of glass composition on the properties of silver-doped radiophotoluminescent phosphate glasses, J. NonCryst. Solids, 1996, vol. 202, pp. 173-177.

31. Hirao, K., Qio, J., and Shimizugawa, Y., Photostimulable luminescence glasses as a novel material for optical memory, Jpn. J. Appl. Phys., 1998, vol. 37, pp. 2259-2264.

32. Poirier, G., Nalin, M., Cescato, L., Messaddeq, Y., and Ribeiro, S., Bulk photochromism in a tungstatephosphate glass: A new optical memory material?, J. Chem. Phys., 2006, vol. 125, p. 161101.

33. Sidorov, A.I., Ignat'ev, A.I., Dubrovin, V.D., and Nikonorov, N.V., The influence of X-ray and UV laser radiation on the optical properties of alkali-containing silicate glasses, Opt. Spectrosc., 2019, vol. 127, pp. 508513.

34. Sidorov, A.I., Nikonorov, N.V., Ignatiev, A.I., and Nemilov, S.V., The effect of UV irradiation and thermal treatments on structural properties of silver-containing photo-thermo-refractive glasses: Studies by Raman spectroscopy, Opt. Mater., 2019, vol. 98, p. 109422.

35. Boizot, B., Agnello, S., Reynard, B., Boscaino, R., and Petite, G., Raman spectroscopy study of $\beta$-irradiated silica glass, J. Non-Cryst. Solids, 2003, vol. 325, pp. 22-28.

36. McIntosh, C., Touluse, J., and Tick, P., The Boson peak in alkali silicate glasses, J. Non-Cryst. Solids, 1997, vol. 222, pp. 335-341.

37. Hehlen, B., Courtens, E., Vacher, R., Yamanaka, A., Kataoka, M., and Inoue, K., Hyper-Raman scattering observation of the Boson peak in vitreous silica, Phys. Rev. Lett., 2000, vol. 84, pp. 5355-5358.

38. Defects in $\mathrm{SiO}_{2}$ and Related Dielectrics: Science and Technology, Ed. by Pacchioni, G., Skuja, L., and Griscom, D.L., NATO Science Series II, Dordrecht: Kluwer, 2000, vol. 2.

39. Quaranta, A., Rahman, A., Mariotto, G., Maurizio, C., Trave, E., Gonella, F., Cattaruzza, E., Gibaudo, E., and Broquin, J.E., Spectroscopic investigation of structural rearrangements in silver ion-exchanged silicate glasses, J. Phys. Chem. C, 2012, vol. 116, pp. 37573764.

40. Osipov, A., Osipova, L., and Zainullina, R., Raman spectroscopy and statistical analysis of the silicate species and group connectivity in cesium silicate glass forming system, Int. J. Spectrosc., 2015, vol. 2015, p. 572840 .

41. Furukawa, T., Fox, K.E., and White, W.B., Raman spectroscopic investigation of the structure of silicate glasses. III. Raman intensities and structural units in sodium silicate glasses, J. Chem. Phys., 1981, vol. 75, pp. $3226-3237$.

42. Kingma, K.J. and Hemley, R.J., Raman spectroscopic studies of microcrystalline silica, Am. Mineral., 1994, vol. 79, pp. 269-273.

43. De Lamaestre, R.E., Bea, H., Bernas, H., Belloni, J., and Marignier, J.L., Irradiation-induced Ag nanocluster nucleation in silicate glasses: Analogy with photography, Phys. Rev. B, 2007, vol. 76, p. 205431. 